\title{
ON EXISTENCE AND STABILIZATION OF THE STRONG SOLUTION OF THE AUTONOMOUS STOCHASTIC PARTIAL DIFFERENTIAL ITO-SKOROKHOD EQUATION WITH RANDOM PARAMETERS
}

\author{
V.K. YASYNSKYY, I.V. YURCHENKO
}

\begin{abstract}
This paper considers the asymptotic behavior of the strong solution of the linear partial stochastic differential Ito-Skorokhod equation in the corresponding space with random parameters. An existence of the strong solution is proved and sufficient conditions for the asymptotic stability and the mean square instability of a strong solution of a similar equation are obtained. The stochastic model of complex systems, which is proposed in this paper, is an attempt to take into consideration the full extent of randomness in the studying of real processes, which are described by differential equations in partial derivatives, on the right side of which a diffuse perturbations of the Brownian process type and random perturbations of other types are taken into consideration.
\end{abstract}

Keywords: stochastic partial differential equation, mean square stability, asymptotic stability.

\section{INTRODUCTION}

Deterministic partial differential equations were considered by many authors, see, for example [1-3] and bibliography therein.

Since the concepts of stochastic differential and integral and change of variables for a stochastic differential have been introduced and a strong solution to a stochastic differential equation (SDE) has been defined in the wellknown monographs [4-6] and then propagated to classes of stochastic functional differential equations [7-9] (see the extensive bibliography in these studies), it became possible to investigate an asymptotically strong solution for SPDE (see, for example [5, 10-12]).

The further analysis of SPDE involves the construction of mathematical models of complicated real systems, which need random parameters to be considered in these equations $[6,7,12,13]$.

In the paper, we will analyze the asymptotic behavior of strong solution of LSPDISE taking into account random parameters in the right-hand side [10, 12].

\section{PROBLEM STATEMENT}

Consider a stochastic experiment with the basic probability space $[1,4,5,7]$ $(\Omega, \mathcal{F}, \mathrm{F}, \mathrm{P}), \quad \mathrm{F} \equiv\left\{\mathcal{F}_{t}, t \geq 0\right\} \quad$ is filtration, where function $u(t, x, \omega) \in \mathrm{R}^{1}$ is given, which is measurable with probability one in $t$ and $x$ with respect to the 
minimum $\sigma$-algebra $\mathcal{B}\left([0, T], \mathrm{R}^{1}\right)$ of Borel sets on the plane $[13,15]$ and for which

$$
\int_{-\infty}^{+\infty} \mathrm{E}\left\{|u(t, x, \omega)|^{2}\right\} d x<\infty
$$

for all $t \in[0, T], E\{\bullet\}$ is expectation [14], and $T \subset[0, \infty)$. Denote by $\mathscr{S}_{T}$ the space of function $\{u(t, x, \omega)\}$, which possesses the integrability property (1).

Introduce the norms $[6,15]$ :

$$
\begin{gathered}
\|u(t, x, \omega)\|_{L_{2 \mathrm{R}} 1}^{2} \equiv \int_{-\infty}^{+\infty}|u(t, x, \omega)|^{2} d x ; \\
\|u(t, x, \omega)\|_{L_{2 T}}^{2} \equiv \int_{0}^{T}|u(t, x, \omega)|^{2} d t \\
\mathrm{E}_{u}(t) \equiv \mathbb{E}\left\{\|u(t, x, \omega)\|_{L_{2 \mathrm{R}}}^{2}\right\},
\end{gathered}
$$

where $L_{2 \mathrm{R}^{1}}$ and $L_{2 T}$ are spaces of functions $\{u(t, x, \omega)\}$, which have the corresponding norms (2)-(4).

In space $\mathscr{M}_{T}$, it is necessary to introduce the norm

$$
\|u(t, x, \omega)\|^{2} \equiv \int_{0}^{T} \mathrm{E}_{u}(t) d t=\int_{0}^{T} \mathrm{E}\left[\int_{-\infty}^{+\infty}|u(t, x, \omega)|^{2} d x\right]^{2} d t .
$$

Denote

$$
Q(A(\xi(\omega)), q, p) \equiv \sum_{k=1}^{n} \sum_{j=1}^{m} a_{k j}(\xi(\omega)) q^{k} p^{j}
$$

where $A \equiv\left\{a_{k j}\right\}$ is a real $n \times m$ matrix composed of elements $a_{k j} \in \mathrm{R}^{1}$.

In space $\mathscr{M}_{T}$ with (5), consider a subspace $\mathscr{M}_{1 T} \subset \mathscr{M}_{T}$, for whose elements the inclusion

$$
Q\left(A, \frac{\partial}{\partial t}, \frac{\partial}{\partial x}\right) u(t, x, \omega) \in \mathscr{M}_{T}
$$

takes place.

On $(\Omega, \mathcal{F}, \mathrm{F}, \mathrm{P})$ consider the Cauchy problem for the linear stochastic partial differential equation (LSPDISE)

$$
\begin{gathered}
\frac{\partial}{\partial t}\left[Q\left(A\left(\xi_{1}(\omega)\right), \frac{\partial}{\partial t}, \frac{\partial}{\partial x}\right) u(t, x, \omega)\right]+Q\left(B\left(\xi_{2}(\omega)\right), \frac{\partial}{\partial t}, \frac{\partial}{\partial x}\right) u(t, x, \omega)= \\
=Q\left(C\left(\xi_{3}(\omega)\right), \frac{\partial}{\partial t}, \frac{\partial}{\partial x}\right) u(t, x, \omega) \frac{d w(t, \omega)}{d t}+ \\
+\int_{\mathbf{V}} Q\left(D\left(\xi_{4}(\omega)\right), \frac{\partial}{\partial t}, \frac{\partial}{\partial x}, v\right) u(t, x, \omega) \widetilde{v}(d t, d v),
\end{gathered}
$$




$$
\left.Q\left(A\left(\xi_{1}(\omega)\right), \frac{\partial}{\partial t}, \frac{\partial}{\partial x}\right) u(t, x, \omega)\right|_{t=0}=[Q u]_{0},
$$

where $Q$ is defined by (6), (7) matrices $B \equiv\left\{b_{i j}\left(\xi_{2}(\omega)\right)\right\}_{i, j=1}^{k, n}, b_{i j}\left(\xi_{2}(\omega)\right) \in \mathbb{R}^{1}$; $C \equiv\left\{c_{i j}\left(\xi_{3}(\omega)\right)\right\}_{i, j=1}^{k, n}, \quad c_{i j}\left(\xi_{3}(\omega)\right) \in \mathrm{R}^{1}, \quad D \equiv\left\{d_{i j}\left(\xi_{4}(\omega), v\right)\right\}_{i, j=1}^{k, n}, d_{i j}\left(\xi_{4}(\omega), v\right) \in$ $\in \mathbf{R}^{1} \times \mathbf{V}$, where $\xi_{i}(\omega), i=1,2,3,4$, are random value specified by the density $p_{\xi_{i}}(x), i=1,2,3,4$, (or by the distribution function $F_{\xi_{i}}(x) \equiv \mathbb{P}\left\{\omega: \xi_{i}(\omega)<x\right.$ $\left.\forall x \in \mathbb{R}^{1}\right\}, i=1,2,3,4$ [14]), $w(t, \omega)$ is a one-dimensional Wiener process [11], and $\xi_{i}(\omega), \quad i=1,2,3,4$, does not depend on $w(t, \omega) . \quad \widetilde{v}(d t, A) \equiv$ $\equiv v(d t, A)-\Pi(A) d t$ is the centered Poisson measure.

By a strong solution of the Cauchy problem (8), (9) we will understand function $u(t, x, \omega)$ continuous in $t \in[0, T]$ with probability one, consistent with filtration $\left\{\mathcal{F}_{t}, t \in[0, T]\right\}$, and such that with probability one for each pair $(t, x)$ it satisfies the integral stochastic equation $[1,4,11]$ :

$$
\begin{aligned}
Q\left(A\left(\xi_{1}(\omega)\right),\right. & \left.\frac{\partial}{\partial t}, \frac{\partial}{\partial x}\right) u(t, x, \omega)=[Q u]_{0}+\int_{0}^{t} Q\left(B\left(\xi_{2}(\omega)\right), \frac{\partial}{\partial x}\right) u(s, x, \omega) d s+ \\
& +\int_{0}^{t} Q\left(C\left(\xi_{3}(\omega)\right), \frac{\partial}{\partial s}, \frac{\partial}{\partial x}\right) u(s, x, \omega) d w(s, \omega) d s+ \\
& +\int_{0}^{t} \int_{\mathbf{V}} Q\left(D\left(\xi_{4}(\omega)\right), \frac{\partial}{\partial s}, \frac{\partial}{\partial x}, v\right) u(s, x, \omega) \widetilde{v}(d s, d v)
\end{aligned}
$$

with the nonrandom initial conditions (9).

\section{EXISTENCE OF THE SOLUTION OF THE CAUCHY PROBLEM FOR LSPDISE}

(8), (9) IN SPACE $\mathscr{M} 1 T$

To establish the existence of a strong solution (10) of the Cauchy problem for (8), (9), we will first prove an auxiliary result.

Lemma 1. The Fourier transform in $x$ [1] for function $u(t, x, \omega)$ :

$$
v(t, \sigma, \omega) \equiv \frac{1}{\sqrt{2 \pi}} \int_{-\infty}^{+\infty} e^{-i \sigma x} u(t, x, \omega) d x
$$

does not bring it out of the space $\mathscr{N}_{T}$ for any finite $T \subset \mathrm{R}^{1}$.

Proof. The existence of the Fourier transform follows from the fact that $u(t, x, \omega)$ lies in $L_{2 \mathbb{R}^{1}}$ with probability one for an arbitrary $t \in[0, T]$ and $\mathrm{P}\left\{\int_{-\infty}^{+\infty}|u(t, x, \omega)|^{2} d x>N\right\} \leq \frac{\mathrm{E}_{u}(t)}{N} \rightarrow 0$ as $N \rightarrow+\infty$. According to the Plancherel theorem [16], $\quad \int_{-\infty}^{+\infty}|v(t, \sigma, \omega)|^{2} d \sigma=\frac{1}{\sqrt{2 \pi}} \int_{-\infty}^{+\infty}|u(t, x, \omega)|^{2} d x, \quad$ i.e. $\quad\|v\|_{L_{2 \mathrm{R}} 1}=$ 
$=\frac{1}{\sqrt{2 \pi}}\|u\|_{L_{2 \mathrm{R}} 1} ;$ therefore $\mathrm{E}_{v}(t)=\frac{1}{\sqrt{2 \pi}} \mathbb{E}_{u}(t)$. Then according to (11) and the definition of a norm in space $\mathscr{M T}_{T}$ we get $\|v\|_{\mathrm{M}_{T}}=\frac{1}{\sqrt{2 \pi}}\|u\|_{\mathrm{M}_{T}}$, which proves Lemma 1.

Theorem 1. Let the following conditions be satisfied for the Cauchy problem (8), (9):

(i) the roots of polynomial $P(\lambda(x), i \sigma) \equiv \lambda Q(A(x), \lambda, i \sigma)+Q(B(x), \lambda, i \sigma)$ for an arbitrary $x \in \mathbb{R}^{1}$ and $\sigma \neq 0$ satisfy the inequality $\operatorname{Re} \lambda(x) \leq \psi(\sigma)<0$, $\psi(0)=0$;

(ii) $\forall t \in[0, T]$ and $C(x) \equiv 0_{k \times n}, D(x) \equiv 0_{k \times n}$ the deterministic equation

$$
\frac{\partial}{\partial t}\left[Q\left(A(x), \frac{\partial}{\partial t}, \frac{\partial}{\partial x}\right) \widetilde{u}(t, x)\right]+Q\left(B(x), \frac{\partial}{\partial t}, \frac{\partial}{\partial x}\right) \widetilde{u}(t, x)=0
$$

has the solution $\widetilde{u}(t, x)$ of the Cauchy problem in $L_{2 \mathrm{R}^{1}}$ with the initial conditions

$$
Q\left(A(x), \frac{\partial}{\partial t}, \frac{\partial}{\partial x}\right) \widetilde{u}(t, x)=[Q \widetilde{u}]_{0} ;
$$

(iii) random variable $\xi_{i}(\omega), i=1,2,3,4$, does not depend on $w(t, \omega)$ and $\widetilde{v}(d t, A)$.

Then the stochastic Cauchy problem (8), (9) for $C(x) \neq 0_{k \times n}$ has a solution in space $\mathscr{M}_{1 T}$.

Proof. Since the Fourier transform [1] preserves the norm in $\mathscr{T}_{1 T}$ by Lemma 1, it will suffice to prove the existence of a strong solution of the Cauchy problem of LSDISE for $v(t, \sigma, \omega)$, given by formula (11), namely,

$$
\begin{gathered}
\frac{d}{d t}\left[Q\left(A\left(\xi_{1}(\omega)\right), \frac{d}{d t}, i \sigma\right) v(t, \sigma, \omega)\right]+Q\left(B\left(\xi_{2}(\omega)\right), \frac{d}{d t}, i \sigma\right) v(t, \sigma, \omega)= \\
=Q\left(C\left(\xi_{3}(\omega)\right), \frac{d}{d t}, i \sigma\right) v(t, \sigma, \omega) \frac{d w(t, \omega)}{d t}+ \\
\left.+\int_{\mathbf{v}} Q\left(D\left(\xi_{4}(\omega)\right)\right), \frac{d}{d t}, i \sigma, v\right) v(t, \sigma, \omega) \widetilde{v}(d s, d v) .
\end{gathered}
$$

Note that for an arbitrary real matrix $D(x) \equiv\left\{d_{i j}(x)\right\}_{i, j=1}^{k, n}$ and for an arbitrary $x \in \mathrm{R}^{1}$ we get the inclusion $Q\left(D(x), \frac{d}{d t}, i \sigma\right) v(t, \sigma, \omega) \in \mathscr{N}_{1 T}$ and solution $v(t, \sigma, \omega)$ of the $\operatorname{LSDE}(14)$ for each $\sigma \neq 0$ exists and is unique up to stochastic equivalence $[3,5,8]$. LSDE (14) should be understood as an integral stochastic equation: 


$$
\begin{gathered}
Q\left(A\left(\xi_{1}(\omega)\right), \frac{d}{d t}, i \sigma\right) v(t, \sigma, \omega)=[Q v]_{0}+\int_{0}^{t} Q\left(B\left(\xi_{2}(\omega)\right), d s, i \sigma\right) v(s, \sigma, \omega)= \\
\quad=\int_{0}^{t} Q\left(C\left(\xi_{3}(\omega)\right), d s, i \sigma\right) v(s, \sigma, \omega) d w(s, \omega)+ \\
+\int_{0}^{t} \int_{\mathbf{V}} Q\left(D\left(\xi_{4}(\omega)\right), \frac{\partial}{\partial s}, \frac{\partial}{\partial x}, v\right) v(\mathrm{~s}, \sigma, \omega) \widetilde{v}(d s, d v),
\end{gathered}
$$

for which the conditions are satisfied that guarantee the existence and uniqueness of a strong solution up to stochastic equivalence [7, Theorem 4.1].

Let $H(t, \sigma)$ be a fundamental solution of the deterministic homogeneous unperturbed Cauchy problem (12), (13) for the LSPDISE (8), (9) for $C(x) \neq$ $\neq 0_{k \times n}$, then the strong solution of LSDE (14) can be written as the integral equation $[9,19]$

$$
\begin{aligned}
v(t, \sigma, \omega)=v_{0}(t, \sigma) & +\int_{0}^{t} H(t-s) Q\left(C\left(\xi_{3}(\omega)\right), d s, i \sigma\right) v(t, \sigma, \omega) d w(s, \omega)+ \\
& +\int_{0}^{t} \int_{\mathbf{V}} y(t-s) Q\left(D\left(\xi_{4}(\omega), i \sigma\right)\right) \widetilde{v}(d s, d v)
\end{aligned}
$$

where $v_{0}(t, \sigma)$ is the solution of the homogeneous unperturbed Cauchy problem

$$
\frac{d}{d t}\left[Q\left(A\left(\xi_{1}(\omega)\right), \frac{d}{d t}, i \sigma\right) v(t, \sigma, \omega)+Q\left(B\left(\xi_{2}(\omega)\right), \frac{d}{d t}, i \sigma\right) v(t, \sigma, \omega)\right]=0 .
$$

According to [1], the fundamental solution $H(t, \sigma)$ has the form

$$
H(t, \sigma)=\frac{1}{\sqrt{2 \pi}} \oint_{\Gamma} \frac{e^{\lambda t} d \lambda}{P(\lambda(x), i \sigma)},
$$

where $\Gamma$ is the contour enveloping all the zeroes of the polynomial $P(\lambda(x), i \sigma)$.

Applying random operator $Q\left(C\left(\xi_{3}(\omega)\right), d t, i \sigma\right)$ to both sides of (15) yields

$$
\begin{gathered}
Q\left(C\left(\xi_{3}(\omega)\right), d t, i \sigma\right) v(t, \sigma, \omega)=Q\left(C\left(\xi_{3}(\omega)\right), d t, i \sigma\right) v_{0}(t, \sigma)+ \\
+\int_{0}^{t} Q\left(C\left(\xi_{3}(\omega)\right), d t, i \sigma\right) H(t-s, \sigma) Q\left(C\left(\xi_{3}(\omega)\right), \frac{\partial}{\partial s}, i \sigma\right) v(s, \sigma, \omega) d w(s, \omega)+ \\
+\int_{0}^{t} Q\left(D\left(\xi_{4}(\omega)\right), \frac{\partial}{\partial s}, i s, v\right) v(s, \sigma, \omega) \widetilde{v}(d s, d v)
\end{gathered}
$$

Considering the squared absolute value of the left- and right-hand sides of (17) and using the inequality $|a+b+c|^{2} \leq 3\left(|a|^{2}+|b|^{2}+|c|^{2}\right)$ yield

$$
\left|Q\left(C\left(\xi_{3}(\omega)\right), d t, i \sigma\right) v(t, \sigma, \omega)\right|^{2} \leq 3\left|Q\left(C\left(\xi_{3}(\omega)\right), d t, i \sigma\right) v_{0}(t, \sigma)\right|^{2}+
$$




$$
\begin{aligned}
& +3\left|\int_{0}^{t} Q\left(C\left(\xi_{3}(\omega)\right), d t, i \sigma\right) H(t-s, \sigma) Q\left(C\left(\xi_{3}(\omega)\right), \frac{\partial}{\partial s}, i \sigma\right) v(s, \sigma, \omega) d w(s, \omega)\right|^{2}+ \\
& +3\left|\int_{0}^{t} \int_{\mathbf{V}} Q\left(D\left(\xi_{4}(\omega)\right), d t, i \sigma, v\right) H(t-s, \sigma) Q\left(D\left(\xi_{4}(\omega)\right), \frac{\partial}{\partial s}, i \sigma, v\right) v(s, \sigma, \omega) \widetilde{v}(d s, d v)\right| .(18)
\end{aligned}
$$

Let

$$
\begin{gathered}
z_{1}(t, \sigma) \equiv \mathbb{E}\left\{\left|Q\left(C\left(\xi_{3}(\omega)\right), d t, i \sigma\right) v(t, \sigma, \omega)\right|^{2}\right\} ; \\
z_{2}(t, \sigma, \omega) \equiv \mathbb{E}\left\{\left|Q\left(D\left(\xi_{4}(\omega)\right), d t, i \sigma, v\right) v(t, \sigma, \omega)\right|^{2}\right\},
\end{gathered}
$$

where $\mathbb{E}\{\bullet\}$ denotes expectation [14]. Applying the operation $\mathbb{E}\{\bullet\}$ to the leftand right-hand sides of inequality (18), considering the property of the Ito integral on the evaluation of $E\{\bullet\}$ of the squared Ito integral [7, p. 245-249] and taking into account condition (iii) of Theorem 1, we get the following inequality:

$$
\begin{gathered}
z(t, \sigma) \leq 3 \mathrm{E}\left|Q\left(C\left(\xi_{3}(\omega)\right), d t, i \sigma\right) v_{0}(t, \sigma)\right|^{2}+ \\
+3 \int_{0}^{t} \mathrm{E}\left|Q\left(C\left(\xi_{3}(\omega)\right), \frac{\partial}{\partial s}, i \sigma\right) H(t-s, \sigma)\right|^{2} z_{1}(s, \sigma) d s+ \\
+3 \int_{0}^{t} \int_{\mathbf{V}} \mathbf{E}\left\{\left|Q\left(D\left(\xi_{4}(\omega), \frac{\partial}{\partial s}, i \sigma, v\right)\right) H(t-s, \sigma)\right|^{2}\right\} z_{2}(s, \sigma, v) d s .
\end{gathered}
$$

Condition $(i)$ of Theorem 1 makes it possible to obtain the inequality [1] $\mathrm{E}\left|Q\left(C\left(\xi_{3}(\omega)\right), d t, i \sigma\right) H(t-s, \sigma)\right|^{2} \leq L$, and condition (ii) defines the uniform boundedness

$$
\begin{gathered}
\mathrm{E}\left|Q\left(C\left(\xi_{3}(\omega)\right), d t, i \sigma\right) v_{0}(t, \sigma)\right|^{2} \leq \frac{K}{2}, \\
\mathrm{E}\left|Q\left(D\left(\xi_{4}(\omega)\right), d t, i \sigma, v\right) v_{0}(t, \sigma)\right|^{2} \leq \frac{K}{2} .
\end{gathered}
$$

The inequalities obtained above and (19) yield the estimate $z_{i}(t, \sigma) \leq \frac{K}{2}+L \int_{0}^{T} z_{i}(s, \sigma) d s, i=1,2$, whence according to the Gronwall inequality [1] we get the exponential estimate

$$
z_{i}(t, \sigma) \leq K e^{L t} \quad \forall t \in[0, T] \subset[0, \infty), i=1,2 .
$$

Thus, the inclusion

$$
\begin{gathered}
Q\left(C\left(\xi_{3}(\omega)\right), d t, i \sigma\right) v(t, \sigma, \omega) \in \mathscr{N}_{T}, \\
Q\left(D\left(\xi_{4}(\omega)\right), d t, i \sigma, v\right) v(t, \sigma, \omega) \in \mathscr{\mathscr { S } _ { T }}
\end{gathered}
$$


is guaranteed. Applying random operator $Q(D(\xi(\omega)), d t, i \sigma)$ to (16), similarly to the above reasoning, we can write the corresponding inequality for any real matrix $D(x) \equiv\left\{d_{i j}(x)\right\}_{i, j=1}^{k, n}$. Therefore, considering estimate (20) and condition (i), we obtain the statement of Theorem 1 .

\section{ASYMPTOTIC MEAN SQUARE BEHAVIOR OF THE STRONG SOLUTION OF THE LSPDISE}

First, let us prove an auxiliary statement.

Lemma 2. Let conditions of Theorem 1 be satisfied for the LSPDISE (8), (9). Then:

(i) for an arbitrary matrix $C(x) \neq 0_{k \times n}$ the inclusion holds

$$
\mathrm{E}\left|Q\left(C\left(\xi_{3}(\omega)\right), d t, i \sigma\right)\right|^{2} H(t, \sigma) \in L_{2,(0,+\infty)} ;
$$

(ii) for the corresponding norm of this space, the equality is true

$$
\left.\mathrm{E} \| Q\left(\xi_{3}(\omega)\right), d t, i \sigma\right) H(t, \sigma) \|_{L_{2 T}}^{2}=\frac{1}{2 \pi} \int_{-\infty}^{+\infty} \frac{\left.\mathrm{E} \mid Q\left(\xi_{3}(\omega)\right), i \lambda, i \sigma\right)\left.\right|^{2}}{|P(i \lambda, i \sigma)|^{2}} d \lambda \equiv S(\sigma)
$$

(iii) for an arbitrary matrix $D(x) \neq 0_{k \times n}$ the inclusion holds

$$
\int_{\mathbf{V}} \mathrm{E}\left|Q\left(D\left(\xi_{4}(\omega)\right), d t, i \sigma, v\right)\right|^{2} H(t, \sigma) \Pi(d \sigma) \in L_{2,(0,+\infty)} ;
$$

(iv) for the corresponding norm of this space, the equality is true

$$
\begin{gathered}
\int_{\mathbf{V}} \mathbb{E}\left\{Q\left(D\left(\xi_{4}(\omega)\right), d t, i \sigma, v\right) H(t, \sigma)\right\} \Pi(d v)= \\
=\frac{1}{2 \pi} \int_{\mathbf{V}} \int_{-\infty}^{+\infty} \frac{E\left|Q\left(D\left(\xi_{4}(\omega)\right), i \lambda, i \sigma, v\right)\right|^{2}}{|P(i \lambda, i \sigma)|^{2}} d \lambda \Pi(d v) \equiv S_{1}(\sigma) .
\end{gathered}
$$

Proof. Using condition ( $i$ ) of Theorem 1 and formula (16), we can calculate

$$
\begin{gathered}
\frac{1}{2 \pi} \int_{0}^{\infty}\left[Q\left(C\left(\xi_{3}(\omega)\right), d t, i \sigma\right) H(t, \sigma) e^{-i \lambda t}\right]=\frac{1}{2 \pi} \frac{Q\left(C\left(\xi_{3}(\omega)\right), i \lambda, i \sigma\right)}{P(i \lambda, i \sigma)} ; \\
\frac{1}{2 \pi} \int_{0}^{\infty} \int_{\mathbf{v}}\left[Q\left(D\left(\xi_{4}(\omega)\right), d t, i \sigma, v\right) H(t, \sigma) e^{-i \lambda t}\right] \Pi(d v)= \\
=\frac{1}{2 \pi} \int_{\mathbf{v}} \frac{Q\left(D\left(\xi_{4}(\omega)\right), i \lambda, i \sigma, v\right)}{P(i \lambda, i \sigma)} \Pi(d v)
\end{gathered}
$$

and multiplying the left- and right-hand sides of abovementioned equalities by $\mathrm{E}\left\{|\bullet|^{2}\right\}$ we obtain statements (22), (24).

To prove (23) and (25), let us apply the Plancherel theorem [1]:

$$
\left\|Q\left(C\left(\xi_{3}(\omega)\right), d t, i \sigma\right) H(t, \sigma)\right\|_{L_{2(0, \infty)}}^{2}=\frac{1}{2 \pi} \int_{-\infty}^{+\infty} \frac{\left|Q\left(C\left(\xi_{3}(\omega)\right), i \lambda, i \sigma\right)\right|^{2}}{|P(i \lambda, i \sigma)|^{2}} d \lambda ;
$$




$$
\begin{aligned}
& \int_{\mathbf{V}} Q\left(D\left(\xi_{4}(\omega)\right), d t, i \sigma, v\right) H(t, \sigma) \Pi(d v)= \\
= & \frac{1}{2 \pi} \int_{\mathbf{v}} \int_{-\infty}^{+\infty} \frac{\left|Q\left(D\left(\xi_{4}(\omega)\right), i \lambda, i \sigma, v\right)\right|^{2}}{|P(i \lambda, i \sigma)|^{2}} d \lambda \Pi(d v) .
\end{aligned}
$$

Multiplying the left- and right-hand sides of the resultant equality by $\mathrm{E}\left\{|\bullet|^{2}\right\}$, we get $S(\sigma), S_{1}(\sigma)$ in formula (23), (25).

Theorem 2. Let the conditions of Theorem 1 be satisfied. Then:

(i) if $\sup S(\sigma)<1$, then $\lim _{t \rightarrow \infty} \mathrm{E}_{U}(t)=0$, where

$$
U(t, x, \omega) \equiv Q\left(R(\xi(\omega)), \frac{\partial}{\partial t}, \frac{\partial}{\partial x}\right) u(t, x, \omega)
$$

for an arbitrary real matrix $R$;

(ii) if $S(\sigma)>1$ on the set $\Lambda$ of the positive Lebesgue measure, then $\lim _{t \rightarrow \infty} \mathrm{E}_{U}(t)=+\infty$.

Proof. Since the positive kernel tends to zero as $t \rightarrow+\infty$, from inequality (18) it follows that $z(t, \sigma)$ tends to zero for $S(\sigma)<1, \sigma \neq 0$.

If the inequality $S(\sigma)<1$, in (24) holds, then it can be easily seen that as $t \rightarrow+\infty$, the absolute value of the Fourier transform $U(t, x, \omega)$ tends to zero for an arbitrary real matrix $R(x) \forall x \in \mathbf{R}^{1}$ [19], uniformly with respect to $\sigma$ if $\sup S(\sigma)<1$. It remains to pass to the limit under the sign of the Lebesgue integral to prove the first part of Theorem 2 .

To prove the second part of Theorem 2, it will suffice to prove that $\lim _{t \rightarrow \infty} \int_{-\infty}^{+\infty} z(t, \sigma) d \sigma=\infty$, since (24) holds.

Indeed, let $S(\sigma)>1$ on the set $\Lambda$ of the positive Lebesgue measure, then $\lim _{t \rightarrow+\infty} z(t, \sigma)=+\infty$, since $z(t, \sigma)>0$. Theorem 2 is proved.

\section{PROBLEM OF THE LOSS OF STABILITY OF A ROD}

In [12], the behavior of a rod subject to "white noise" is analyzed. Let the mathematical model of this process be the following stochastic partial differential equation with the derivative of the Wiener process that does not exist with probability one and in the generalized sense the one is a normal "white noise" (see [20]), namely:

$$
\frac{\partial^{4} u}{\partial x^{4}}-a\left(\xi_{1}(\omega)\right) \frac{\partial^{2} u}{\partial x^{2}}+b\left(\xi_{2}(\omega)\right) \frac{\partial^{2} u}{\partial t^{2}}-c\left(\xi_{3}(\omega)\right) \frac{\partial u}{\partial t}=\frac{\partial^{2} u}{\partial x^{2}} \frac{d w(t, \omega)}{d t},
$$

with the initial conditions

$$
u(0, x)=f_{1}(x), \quad \frac{\partial u(0, x)}{\partial t}=f_{2}(x)
$$


and boundary conditions

$$
u(t, 0)=u(t, l)=\frac{\partial u(t, 0)}{\partial x}=\frac{\partial u(t, l)}{\partial x}=\frac{\partial^{2} u(t, 0)}{\partial x^{2}}=\frac{\partial^{2} u(t, l)}{\partial x^{2}}=0 .
$$

Here $a\left(\xi_{1}(\omega)\right)>0, b\left(\xi_{2}(\omega)\right)>0, c\left(\xi_{3}(\omega)\right)>0$ with probability 1 . Function $u(t, x, \omega)$ is random function, which has no gaps of the second type, i.e., is integrable in the sense of paragraph 1 . Similarly to the discrete case [12], the statistical stability margin $S_{a}^{2}$ with respect to the parameter $a(x) \forall x \in \mathrm{R}^{1}$, is determined as the most admissible intensity of processes with mutually independent values for which the system is stable in li.m., i.e., the solution is stabilized to zero.

As a result, we can calculate the statistical stability margin [17] $S_{k_{1} k_{2}}$ of system (26)-(28)

$$
S_{k_{1} k_{2}} \equiv \sum_{k=0}^{m} a_{k_{1} k_{2}}(\xi(\omega)) \frac{\partial^{k} u(t, x)}{\partial t^{k_{1}} \partial x^{k_{2}}}
$$

with respect to parameters $a_{k_{1} k_{2}}\left(\xi_{1}(\omega)\right), k=k_{1}+k_{2}$.

If we denote $P(\lambda, \sigma, \omega) \equiv \sum_{k=0}^{m} a_{k_{1} k_{2}}\left(\xi_{1}(\omega)\right) \lambda^{k_{1}}(i \sigma)^{k_{2}}$, then the statistical stability margin $S_{k_{1} k_{2}}(x)$ of the system can be calculated by the formula

$$
S_{k_{1} k_{2}}(x) \equiv\left[\sup _{\sigma} \frac{1}{2 \pi} \int_{-\infty}^{+\infty} \frac{|\lambda|^{k_{1}}|\sigma|^{k_{2}}}{|P(i \lambda, \sigma, x)|} d \lambda\right]^{-1} .
$$

Using the above statements (29), (30), the statistical stability margin $S(x)$ with respect to the parameters $a(x), b(x), c(x)$ of system (26)-(28) is found:

$$
S(x) \equiv\left[\sup _{\sigma} \frac{1}{2 \pi} \int_{-\infty}^{+\infty} \frac{\sigma^{2} d \lambda}{\left(\sigma^{4}+a(x) \sigma^{2}-b(x) \lambda^{2}\right)^{2}+c(x)^{2} \lambda^{2}}\right]^{-1}=2 a(x) c(x), \forall x \in \mathbb{R}^{1} .
$$

Thus, system (26)-(28) is stable in 1.i.m., for which $S(x)>\varepsilon^{2}, \forall x \in \mathrm{R}^{1}$.

Let the right-hand side of Eq. (26) in system (26)-(28) be subject to external random disturbances $\xi(\omega)$. This becomes possible if we place the system on a platform whose inching movement can be described by $\varphi_{i}(\xi(\omega)), i=1,2$. Then (26) becomes

$$
\frac{\partial^{4} u}{\partial x^{4}}-a \frac{\partial^{2} u}{\partial x^{2}}+b \frac{\partial^{2} u}{\partial t^{2}}-c \frac{\partial u}{\partial t}=\varphi_{1}(\xi(\omega)) \frac{\partial^{2} u}{\partial x^{2}} \frac{d w(t, \omega)}{d t} .
$$

Using the definition of the statistical stability margin for system (31), (27), (28), we get

$$
S\left(\varphi_{i}\right) \equiv\left[\mathrm{E}\left\{\left|\varphi_{i}(\xi)\right|^{2}\right\} \sup _{\sigma} \frac{1}{2 \pi} \int_{-\infty}^{+\infty} \frac{\sigma^{2} d \lambda}{\left(\sigma^{4}+a \sigma^{2}-b \lambda^{2}\right)^{2}+c^{2} \lambda^{2}}\right]^{-1}=\mathbb{E}\left\{\left|\varphi_{i}(\xi)\right|^{2}\right\} 2 a c .
$$


Applying the sufficient conditions of stability in 1.i.m. from Theorem 2, we conclude that system (27), (28) is stable in li.m. if

$$
E\left\{\varphi_{1}^{2}(\xi(\omega))\right\} 2 a c<1,
$$

and is unstable in l.i.m. otherwise.

Let $\varphi_{2}(\xi(\omega)) \equiv 0, \quad \varphi_{1}(\xi(\omega)) \equiv \varphi(\xi(\omega)) ; \quad \xi(\omega)$ have the distribution law $P\{\omega: \xi \equiv \mathbf{1}\}=P\{\omega: \xi=-1\}=\frac{1}{2} \quad$ and $\quad \varphi(\xi(\omega)) \equiv \xi(\omega) . \quad$ Then $\quad \mathrm{E}\{\xi\}=0$, $D\{\xi\}=1$ and condition coincides with (32).

Let $\varphi_{2}(\xi(\omega)) \equiv 0, \varphi_{1}(\xi(\omega)) \equiv \varphi(\xi(\omega))$. If for the distribution law of $\xi(\omega)$ we take the Poisson law $\mathbb{P}\{\omega: \xi=k\}=\frac{\lambda^{k}}{k !} e^{-\lambda}$ and $\varphi(\xi)=\xi$, тоді $\mathrm{E} \xi=D \xi=\lambda$.

Therefore, the condition of stability in 1.i.m. of system (31), (27), (28) becomes $2 a c \lambda<1$, and that of instability, respectively, $2 a c \lambda>1$.

\section{CONCLUSIONS}

The stochastic model of complicated systems proposed in the paper is apparently the first attempt to take randomness into account to the fullest extent in the analysis of real processes described by partial differential equations whose right-hand sides consider not only diffusion disturbances such as Brownian process $[5,10$, $18,19]$ but random disturbances of other types as well.

\section{REFERENCES}

1. Беллман Р. Дифференциально-разностные уравнения / Р. Беллман, К. Кук. М.: Мир, 1967. - 548 c.

2. Михлин С.Г. Линейные уравнения в частных производных / С.Г. Михлин. М.: Наука, 1997. — 495 с.

3. Степанов В.В. Курс дифференциальных уравнений / В.В. Степанов. - М.: Наука, 1978. - $521 \mathrm{c}$.

4. Гулинский А.В. Теория случайных процессов / А.В. Гулинский, А.Н. Ширяев. - М.: Физ матлит, 2005. - 408 c.

5. Гихман И.И. Стохастические дифференциальные уравнения и их применение / И.И. Гихман, А.В. Скороход. - К.: Наук. думка, 1980. - 612 с.

6. Гихман И.И. Управляемые случайные процессы / И.И. Гихман, А.В. Скороход. - К.: Наук. думка, 1977. — 251 с.

7. Королюк В.С. Ймовірність, статистика та випадкові процеси. Теорія та комп'ютерна практика: в 3-х т. Т.3: Випад кові процеси. Теорія та комп’ютерна практика / В.С. Королюк, Є.Ф. Царков, В.К. Ясинський. Чернівці: Вид-во “Золоті литаври”, 2009. — 798 с.

8. Царьков Е.Ф. Квазилинейные стохастические дифференциальнофункциональные уравнения / Е.Ф. Царьков, В.К. Ясинский. - Рига: Ориентир, 1992. - 301 с.

9. Царьков Е.Ф. Случайные возмущения дифференциально-функциональных уравнений при случайных возмущениях их параметров Е.Ф. Царьков. Рига: Зинатне, 2989. — 421 с. 
10. Гихман И.И. Стохастические дифференциальные уравнения с частными производными: сб. науч. тр / И.И. Гихман, А.В. Скороход. - К.: Ин-т математики АН УССР. - 1981. - С. 25-59.

11. Дороговцев А.Я. поведение решений уравнения теплопроводности с белым шумом в правой части / А.Я. Дороговцев, С.Д. Ивасишен, А.Г. Кукуш // Укр. мат. журн. - 1985. - 37, №1. - С.13-20.

12. Перун Г.М. Исследование задачи Коши для стохастических уравнений в частных производных / Г.М. Перун, В.К. Ясинский // Укр. мат. журн. 1993. - Т.45, № 9. - С.1773-1781.

13. Дынкин Е.Б. Марковские процессы / Е.Б. Дынкин. - М.: Физматгиз, 1969. 859 c.

14. Королюк В.С. Ймовірність, статистика та випад ко ві процеси. Теорія та комп'ютерна практика: в 3 т. Т.1.: Ймовірність / В.С. Королюк, Є.Ф. Царков, В.К. Ясинський. - Теорія та комп'ютерна практика. Чернівці: Золоті литаври, 2007. - 444 с.

15. Колмогоров А.Н. Элементы теории функций и функционального анализа / А.Н.Колмогоров, С.В. Фомин. - М.: Наука, 1976. - 541 с.

16. Хасьминский P.3. Устойчивость систем дифференциальных уравнений при случайных возмущениях их параметров / Р.3. Хасьминский. - М.: Наука, 1969. - 367 с.

17. Эйдельман С.Д. Параболические системы / С.Д. Эйдельман. - М.: Наука, 1964. - 445 с.

18. Donez N.P. Mean Square Behavior of the Strong Solution of a Linear nonAutonomous Stochastic Partial Differential Equation with Markov Parameters / N.P. Donez, I.V. Yurchenko, V.K. Yasynskyy // Cybernetics and System Analysis. - 2014. — Vol. 50, N 6. — P. 930-939. doi:10.1007/s10559-014-9683-8

19. Koroliuk V.S. Behavior of the Second Moment of the Solution to the Autonomous Stochastic Linear Partial Differential Equation with Random Parameters in the Right-Hand Side / V.S. Koroliuk, I.V. Yurchenko, V.K. Yasynskyy // Cybernetics and Systems Analysis. - 2015. - Vol. 51, N 1. - P. 56-63. doi:10.1007/s10559-015-9697-х

20. Булинский А.В. Теория случайных процессов / А.В. Булинский, А.Н. Ширяев. — Москва: Физматлит, 2005. - 402 с.

Received 19.07.2018

From the Editorial Board: the article corresponds completely to submitted manuscript. 